\title{
Lapurdum
}

LAPURDUM Euskal ikerketen aldizkaria | Revue d'études basques |

Revista de estudios vascos | Basque studies review

$3 \mid 1998$

Numéro III

\section{Onomastique basque aux Philippines}

Michel Morvan

\section{OpenEdition}

Journals

Édition électronique

URL : https://journals.openedition.org/lapurdum/1667

DOI : 10.4000/lapurdum. 1667

ISSN : 1965-0655

Éditeur

IKER

Édition imprimée

Date de publication : 1 octobre 1998

Pagination : 33-35

ISBN : 2-84127-152-8

ISSN : $1273-3830$

\section{Référence électronique}

Michel Morvan, «Onomastique basque aux Philippines », Lapurdum [En ligne], 3 | 1998, mis en ligne le 01 septembre 2010, consulté le 25 février 2022. URL : http://journals.openedition.org/lapurdum/1667 ; DOI : https://doi.org/10.4000/lapurdum. 1667 


\section{Michel MORVAN}

\section{ONOMASTIQUE BASQUE AUX PHILIPPINES}

En l'an de grâce 1521 , le 16 mars, le célèbre navigateur conquérant portugais au service de l'Espagne, Ferdinand Magellan, aborde par l'est cet ensemble d'îles innombrables (près de sept mille!) de l'Océan Pacifique qui prendra bientôt le nom de Philippines. L'ensemble en question était peuplé de Negritos de type mélanésien (sans aucun doute les plus anciennes ethnies) et de Philippins asiatiques proprement dits venus par la suite de Malaisie et d'Indonésie. Les Musulmans avaient déjà pris pied sur l'archipel et étendu leur pouvoir sur tout le pays à l'arrivée des Espagnols. L'islam ne subsiste plus aujourd'hui que dans le sud de l'île de Mindanao essentiellement.

Magellan n'ira pas loin. La mort l'attend après cette ultime conquête. Débarqué sur une petite île quasiment inhabitée nommée Homonhon, près de la grande île de Leyte, il se dirige vers l'intérieur, dans ces îles dites Visayas, en direction de l'île centrale de Cebu (voir la carte jointe). Arrivé devant Cebu, sur l'île de Mactan, il plante une croix et déclare prendre possession de tout le pays au nom de l'Espagne. Mais le destin est là. Il est philippin, courageux et se nomme Lapu-Lapu. Magellan est tué dans la bataille contre ce chef autochtone.

Les Espagnols ne renoncent pas pour autant bien sûr et c'est Ruy Lopez de Villalobos qui débarque à son tour en 1543 et donne son nom à l'archipel, Filipinas, en l'honneur du roi Philippe II d'Espagne. L'occupation espagnole devient bien réelle cette fois. Elle se concrétise définitivement en novembre 1565 avec l'arrivée de la flotte de Miguel Lopez de Legazpi sur l'île de Bohol où il lie amitié avec le chef local Rajah Sikatuna, puis occupe Cebu où il fait construire un fort. En 1571 Legazpi s'empare de Manille et de tout le pays dans l'année qui suit, à l'exception de Mindanao et des îles Sulu qui restent aux mains des Musulmans. De nombreuses églises sont bâties et la propagation du catholicisme est fulgurante. Il faut rappeler en effet ici que les Philippines constituent le seul pays chrétien et catholique d'Asie avec près de $95 \%$ de catholiques pratiquants.

Les Philippines seront administrées fermement depuis le Mexique jusqu'en 1821 et les rares tentatives des Hollandais, Portugais et Chinois pour y prendre pied sont repoussées avec succès. Toutefois les Anglais occupent Manille en 1762 mais pour peu de temps et se retirent selon les conditions d'un traité signé à Paris en 1763. En 1872 éclate dans l'armée la première révolte des Philippins contre les Espagnols, à Cavite. La révolte est vite matée, mais désormais l'idée d'indépendance est devenue irrépressible. C'est à la faveur d'une guerre hispano-américaine qui éclate en 1898 et dont le vainqueur est l'Amérique que les Philippins proclament leur indépendance. Mais c'est une indépendance théorique, car les Américains ne la reconnaissent pas. Là commencent le déclin espagnol et l'américanisation du pays qui ira en s'accentuant tout au long du $\mathrm{XX}^{\mathrm{e}}$ siècle, à une 
exception près, celle de la religion. Si la langue espagnole est de moins en moins parlée au profit de l'anglo-américain dont le prestige va grandissant et s'est encore accru depuis la seconde guerre mondiale, le catholicisme en revanche n'a pas pris une ride et la ferveur religieuse demeure intacte et extrêmement forte.

On pourrait penser que l'anglo-américain a absorbé bon nombre de termes espagnols, mais il n'en est rien. L'anglo-américain est devenu une seconde langue à part entière. C"est dans les langues vernaculaires, le tagalog en premier lieu et dans les dialectes locaux (le plus important est celui des Visayas ou cebuano) que l'on trouve les restes du passé linguistique espagnol, parfois arrangés à la sauce locale : noms des jours de la semaine par exemple avec Huwébes, Biyérnes pour "jeudi, vendredi", kumustá pour "comment ça va ?", kuwárto "chambre", kabáyo "cheval", walá probléma "pas de problème" et autres curiosités.

Le basque n'était évidemment pas parlé aux Philippines. En revanche personne, bien sûr, ne distinguait les Basques des Espagnols, et c'est ainsi que l'on trouve des noms de villes et des noms de personnes basques dans ce pays. Les noms de familles sont portés par toute la population et le mélange des noms philippins et des noms espagnols est total. Ce ne sont pas seulement les descendants de la classe dirigeante espagnole qui portent les noms basques et espagnols : on trouve aussi bien des Philippins de pure souche asiatique autochtone portant des noms comme Aguilar et... Yturburu!

Si Legazpi, étant donné le rôle historique important qu'il a joué, a donné son nom à une ville du pays (de même que le chef Lapu-Lapu déjà évoqué à propos de Magellan), on trouvera également Hernani et Oroquieta à côté d'autres noms transposés comme Toledo, Compostela ou Trinidad.

Michel MORVAN

UPRESA 5478 Bordeaux III-CNRS 
35

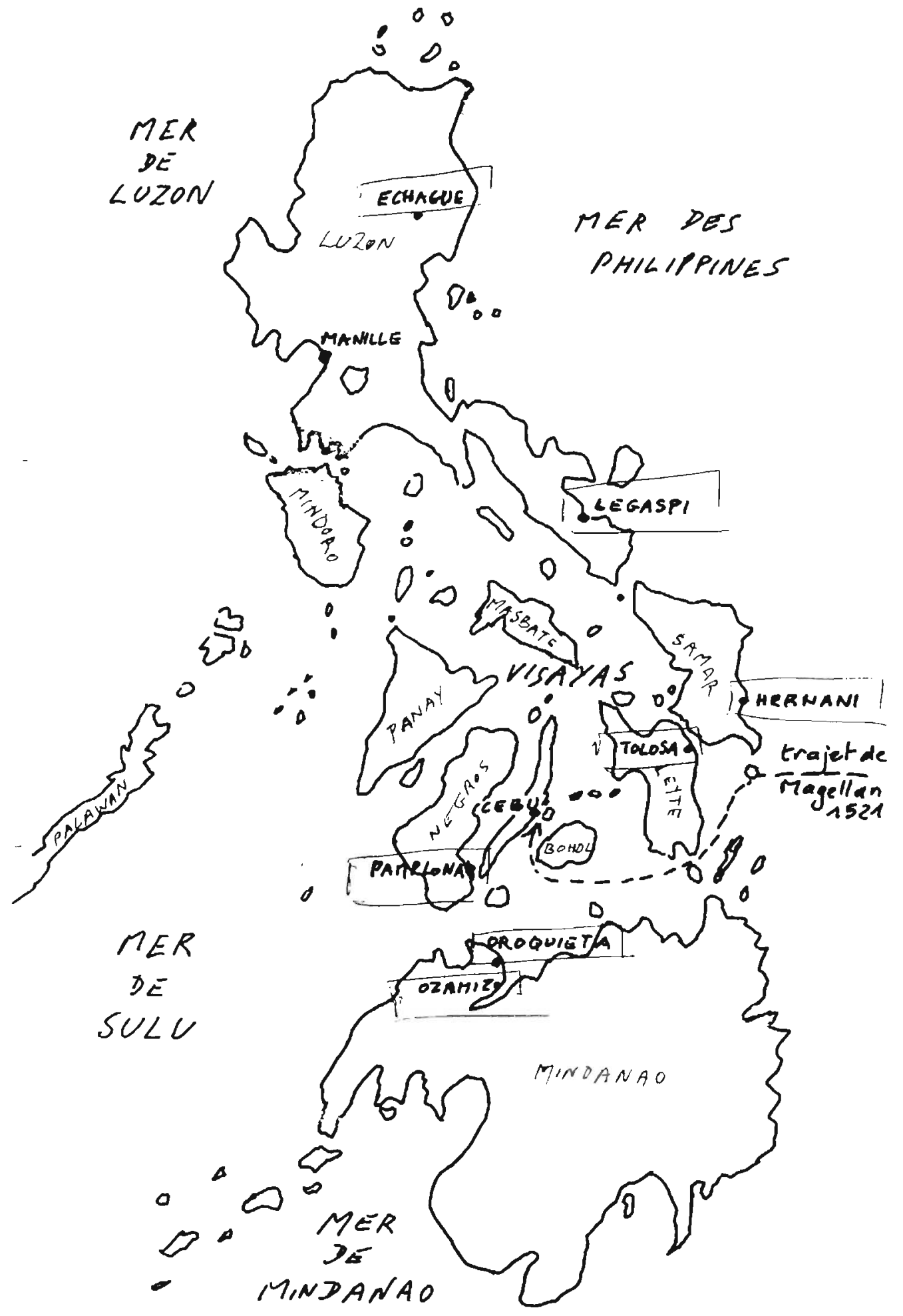

